\title{
Clinical Reasoning: A 77-year-old man presenting with episodic expressive aphasia
}

Alice Shanklin, BS, * Andrew Cox, PhD, * Hamdy M.A. Ahmed, MD, Alicia Lieberman, MD, MS, and Ania Busza, MD, PhD

Neurology ${ }^{\circledR}$ 2018;90:e1822-e1826. doi:10.1212/WNL.0000000000005525
Correspondence

Dr. Busza

ania_busza@

urmc.rochester.edu

\section{Section 1}

A 77-year-old white man presented to the emergency department with a 1-week history of episodic expressive aphasia, lasting between 3 and 30 minutes and increasing in frequency. $\mathrm{He}$ denied any associated symptoms with the aphasia and between episodes returned to baseline. His medical history included psoriatic arthritis, remote biopsy-confirmed giant cell arteritis (GCA), and metastatic urothelial adenocarcinoma for which he was being treated with programmed death ligand 1 (PD-L1) checkpoint inhibitor therapy.

Initial neurologic examination, including language evaluation, was normal. The patient's musculoskeletal examination revealed features of chronic arthritis with dorsal hand soft tissue atrophy and bony joint hypertrophy without active synovitis. There were no findings of cutaneous, cardiopulmonary, or gastrointestinal abnormalities.

The patient's initial brain MRI (figure) showed acute infarction in the right internal capsule. MRI fluid-attenuated inversion recovery sequence was otherwise unremarkable with minimal evidence of small vessel disease. CT angiogram was striking for several focal areas of high-grade stenosis of the large intracranial vessels: the right internal carotid artery (ICA) terminus, the proximal left M1 segment, and the left A1 origin had near-complete stenosis. In contrast, the other intracranial and extracranial neck vessels were patent with minimal atherosclerotic disease.

The patient was started on dual antiplatelet therapy (aspirin and Plavix) as well as high-dose statin for severe, symptomatic large vessel intracranial stenosis.

\section{Questions for consideration:}

1. What are the potential causes of focal proximal stenosis of the large intracranial arteries?

2. Given this differential diagnosis, what additional workup is recommended?

\section{GO TO SECTION 2}

\footnotetext{
*These authors contributed equally to this work.
}

From the University of Rochester School of Medicine and Dentistry (A.S., A.C.); Department of Medicine (H.M.A.A.), Rochester Regional Health; and Department of Medicine, Division of Allergy, Immunology, and Rheumatology (A.L.), and Department of Neurology (A.B.), University of Rochester Medical Center, NY.

Go to Neurology.org/N for full disclosures. Funding information and disclosures deemed relevant by the authors, if any, are provided at the end of the article. 
Figure Brain MRI and vessel imaging
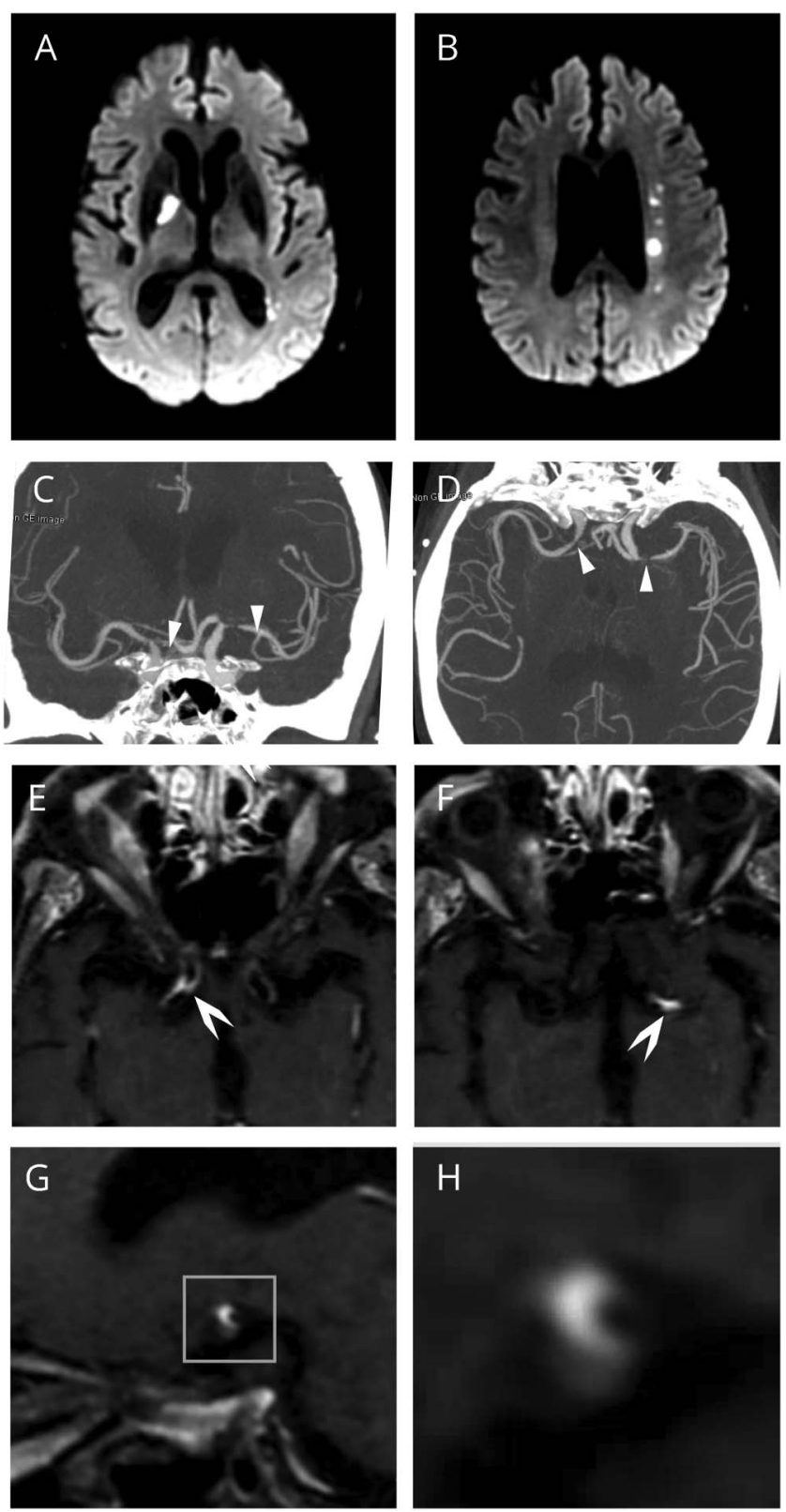

Diffusion-weighted imaging (DWI) with acute ischemic infarcts in the right internal capsule (A) and left corona radiata (B). Coronal (C) and axial (D) CT angiography demonstrates high-grade focal narrowing in the right internal carotid artery (ICA) terminus and M1 segment of the left middle cerebral artery (MCA). These findings are nonspecific and may be seen in atherosclerotic disease. To further investigate the areas of stenosis, high-resolution contrast-enhanced vessel wall imaging (black blood T1-weighted MRI) was obtained. There is significant intramural enhancement in the right ICA terminus (E) and left proximal MCA (F) at the areas of maximal luminal narrowing. (G) shows a sagittal section through the left MCA, enlarged in $(H)$ to demonstrate the crescent-shaped enhancement consistent with vessel wall inflammation. These findings strongly suggest vasculitis. 


\section{Section 2}

Intracranial large vessel narrowing can be due to intracranial atherosclerotic disease, vasculitis, vasospasm, or infection. Intracerebral atherosclerosis is the most common etiology, associated with $5 \%-10 \%$ of ischemic infarctions in white patients and an even larger percent of ischemic infarcts in African American and Asian patients. ${ }^{1}$ Intracranial large vessel stenosis can also be associated with infections including herpesviruses (varicella-zoster virus [VZV], cytomegalovirus, Epstein-Barr virus), borreliosis, syphilis, and HIV. Vessel narrowing due to vasospasm is seen in cocaine use and in reversible cerebral vasoconstrictive syndrome or non-inflammatory vasculopathies such as fibromuscular dysplasia and moyamoya disease. Finally, vasculitis (both primary CNS and systemic) can present with isolated focal intracranial large vessel narrowing. This includes giant cell arteritis, Takayasu arteritis, and granulomatous angiitis. Systemic lupus, Behçet disease, antineutrophil cytoplasmic autoantibody (ANCA)-associated vasculitis, polyarteritis nodosa, and cyroglobulinemic vasculitis have also been associated with intracranial vasculitis, although with accompanying extraneurologic clinical manifestations. In intravascular lymphoma, a rare variant of large B-cell lymphoma, small and medium-sized vessels are narrowed due to tumor cell infiltration of the vessel wall.

Additional workup should therefore include testing for risk factors associated with atherosclerotic disease, systemic and CNS infectious evaluation, CSF studies, markers of systemic inflammation, and a rheumatologic workup with rheumatoid factor, antinuclear antibodies (ANA), and ANCA screening. Brain imaging including $\mathrm{CT}$ and MRI with angiography is indicated. A high-resolution vessel wall contrast-enhanced black blood T1-weighted MRI can also provide valuable information regarding vessel inflammation. ${ }^{2,3}$

In our patient, brain magnetic resonance angiography (MRA) revealed substantial intramural enhancement along the right supraclinoid ICA extending into the M1 segment and similar enhancement extending into the proximal left M1 segment, highly suggestive of vasculitis. His low-density lipoprotein of
$96 \mathrm{mg} / \mathrm{dL}$ and $\mathrm{A} 1 \mathrm{C}$ of $5.9 \%$ were reassuring against chronic metabolic risk factors. His systemic inflammatory markers were modestly elevated with a C-reactive protein of 24 and sedimentation rate of 40 . The patient's rheumatologic workup revealed negative ANA and ANCA screens, normal C3 and C4 complement protein values, and a low positive rheumatoid factor of $20 \mathrm{IU} / \mathrm{mL}$. Echocardiography was unremarkable. Infectious evaluation including blood and CSF cultures and rapid PCR studies for herpes simplex virus (HSV)-1, HSV-2, and VZV were all negative. CSF analysis revealed a total protein of $62 \mathrm{mg} / \mathrm{dL}$, glucose of $62 \mathrm{mg} / \mathrm{dL}$, and no oligoclonal bands, but an elevated immunoglobulin $\mathrm{G}$ index of $8.4 \mathrm{mg} / \mathrm{dL}$. Flow cytometry of the CSF cells was negative for malignancy.

Further investigation into the patient's outside medical records confirmed prior diagnosis of psoriatic arthritis treated with weekly low-dose methotrexate and daily $5 \mathrm{mg}$ prednisone. Fourteen years prior to presentation, he developed a new, severe headache and elevated inflammatory markers, and underwent right temporal artery biopsy consistent with GCA. He was continued on daily prednisone and weekly methotrexate and his GCA, as well as inflammatory arthritis, remained in clinical remission on therapy for years. Nine years prior to presentation, he was diagnosed with stage IV high-grade muscle-invasive urothelial bladder carcinoma. Initially this was managed surgically and later with gemcitabine with cisplatin. Weekly methotrexate was discontinued when receiving chemotherapy. Seven months prior to presentation, due to metastatic cancer progression, our patient had started treatment with atezolizumab, a PD-L1 checkpoint inhibitor, and his daily $5 \mathrm{mg}$ of prednisone was discontinued.

Given the patient's history of GCA, the laboratory findings, and MRA consistent with bilateral intracranial vasculitis, it was believed that his presentation was most consistent with intracranial GCA, relapsed in the setting of stopping immunosuppressive therapy and starting checkpoint inhibitor therapy.

\section{Questions for consideration:}

1. What is GCA and how is it typically treated?

2. How is GCA treatment different if involving the intracranial vessels? 


\section{Section 3}

GCA is the most common vasculitis in persons over age 50. There is an observed 2- to 3 -fold female-to-male predilection and annual incidence increases with age, affecting 1 in 5,000 adults in their 9th decade. ${ }^{4}$ This vasculitis typically affects branches of the aorta and external carotid. Incidence of lifetime GCA-related strokes is $2 \%-7 \%$ in biopsy-proven cases. ${ }^{4-6}$ Interestingly, the majority of these strokes occur within the first year of GCA diagnosis, leading to the accepted practice of initiating antiplatelet agents, generally low-dose aspirin, with immunosuppressive treatment. ${ }^{4}$ Unlike our patient's presentation, over $75 \%$ of GCA-related strokes involve the vertebral system. ${ }^{5}$ High-dose systemic corticosteroids are the standard treatment of GCA. The initial route and dose depends on the severity of the presentation with pulse dosing followed by 1 $\mathrm{mg} / \mathrm{kg} / \mathrm{d}$ tapering over 6-12 months commonly employed. There are currently no published guidelines for using steroid-sparing immunomodulatory agents; however, there is growing evidence for use of anti-interleukin-6 (tocilizumab) as well as $\mathrm{T}$ cell costimulation inhibition (abatacept) along with corticosteroids to decrease GCA relapse rate and improve outcomes. ${ }^{7,8}$

Management of GCA-related stroke requires potent immunosuppression with high-dose systemic corticosteroids. Pulse dosing or $1-2 \mathrm{mg} / \mathrm{kg} / \mathrm{d}$ of methylprednisolone have been used but neither dosing regimen has been found superior. ${ }^{4}$ Patient survival of GCA-related stroke is poor and not all patients respond to initial steroid treatment. ${ }^{4,5}$ Use of cyclophosphamide is also described for severe or refractory cases of GCA. The addition of antiplatelet agents and low molecular weight heparin is also reported but the utility of these agents has yet to be proven. ${ }^{5}$ Therefore, no true standard of care has been established for GCA-related strokes.

Our patient had several episodes of word-finding difficulty that began a few days after admission. These were initially responsive to IV hydration and Trendelenburg positioning. He was started on high-dose IV methylprednisolone $1 \mathrm{mg} /$ $\mathrm{kg} / \mathrm{d}$ once reactivation of GCA was suspected. These episodes increased in frequency and duration, and by day 5 the patient had persistent dysfluency and difficulties following verbal commands. Subsequent MRI found new areas of ischemia in the left middle cerebral artery (MCA) territory. Despite escalation to pulse dose steroids and addition of cyclophosphamide, he had complete left MCA infarction with hemorrhagic transformation. His family ultimately decided to pursue comfort measures and the patient died 2 weeks later. His family declined autopsy.

\section{Discussion}

Our patient had been treated with atezolizumab, a monoclonal antibody targeting programmed death ligand 1 (PD-L1).
This is an immunomodulatory agent within the class of immune checkpoint inhibitors (ICI). ${ }^{9}$ Cancer cells have been shown to harness the innate immune checkpoint system to thwart immunosurveillance defenses. Inhibiting the checkpoint system allows the immune system to recognize and kill cancer cells. ${ }^{10}$ Inhibiting immune system checkpoint mechanisms may also prevent the elimination of harmful, autoreactive lymphocytes and lead to the diverse autoimmune complications observed. ${ }^{11}$

Immune adverse events related to ICI are a relatively new and increasingly recognized phenomenon. These events can manifest as autoimmune disease mimics with features such as inflammatory arthritis, colitis, pneumonitis, nephritis, and myocarditis. ${ }^{11}$ There are sparse but increasing reports of reactivation of preexisting autoimmune disease with use of checkpoint inhibitor therapy. Prompt recognition, discontinuation of the ICI, and treatment of autoimmune manifestations is needed., ${ }^{9,11}$ Neurologic complications of checkpoint inhibitor therapies are also increasingly recognized, including headache, seizures, cranial neuropathies, and polyneuropathy. ${ }^{12} \mathrm{~A}$ recent report ${ }^{13}$ found that $2.9 \%$ of a 347-patient cohort treated with anti-PD1 therapy developed neurologic complications (predominantly myopathies and neuropathies). Cerebral vasculitis has been reported as a result of PD-1 inhibition in a recent case report. ${ }^{14}$ Of note, vasculitis (including cerebral vasculitis) has also been reported after gemcitabine and cisplatin exposure, ${ }^{15,16}$ which the patient had previously received. However, the associated vasculitis in these reports occurred within months of drug exposure, and our patient's chemotherapy began over 7 years prior to presentation.

Our patient died of a severe intracerebral manifestation of relapsed GCA. Checkpoint inhibitors are revolutionizing the treatment of many solid tumors and are gaining in popularity. This devastating case of GCA reactivation highlights the need for prompt recognition and appropriate treatment of immune adverse events associated with anti-PD-L1 and anti-PD-1 therapies.

\section{Author contributions}

A. Shanklin and Dr. Cox: drafting and revision of the manuscript and design, acquisition of data, analysis and interpretation. Drs. Lieberman and Ahmed: drafting and revision of the manuscript, chart and literature review. Dr. Busza: study concept and design, figure and figure legend, critical revision of the manuscript for important intellectual content, supervision.

\section{Study funding}

Preparation of this manuscript was supported in part by NIH National Research Service Award Institutional Research Training Grant 2T32NS007338-16 to the University of Rochester providing support for A.B.

\section{Disclosure}

The authors report no disclosures relevant to the manuscript. Go to Neurology.org/N for full disclosures. 


\section{References}

1. Sacco RL, Kargman DE, Gu Q, et al. Race-ethnicity and determinants of intracranial atherosclerotic cerebral infarction: The Northern Manhattan Stroke Study. Stroke $1995 ; 26: 14-20$

2. Mossa-Basha M, Hwang WD, De Havenon A, et al. Multicontrast high-resolution vessel wall magnetic resonance imaging and its value in differentiating intracranial vasculopathic processes. Stroke 2015;46:1567-1573.

3. Siemonsen S, Brekenfeld C, Holst B, et al. 3 T MRI reveals extra- and intracranial involvement in giant cell arteritis. Am J Neuroradiol 2014:91-97.

4. Lariviere D, Sacre K, Klein I, et al. Extra- and intracranial cerebral vasculitis in giant cell arteritis: an observational study. Med 2014;93:e265.

5. de Boysson H, Liozon E, Larivière D, et al. Giant cell arteritis-related stroke: a retrospective multicenter case-control study. J Rheumatol 2017;44:297-303.

6. Gonzalez-Gay MA, Vazquez-Rodriguez TR, Gomez-Acebo I, et al. Strokes at time of disease diagnosis in a series of 287 patients with biopsy-proven giant cell arteritis. Medicine 2009;88:227-235.

7. Stone JH, Tuckwell K, Dimonaco S, et al. Trial of tocilizumab in giant-cell arteritis. N Engl J Med 2017;377:317-328.

8. Langford CA, Cuthbertson D, Ytterberg SR, et al. A randomized, double-blind trial of abatacept (CTLA-4Ig) for the treatment of giant cell arteritis. Arthritis Rheumatol 2017;69:837-845.
9. Puzanov I, Diab A, Abdallah K, et al. Managing toxicities associated with immune checkpoint inhibitors: consensus recommendations from the Society for Immunotherapy of Cancer (SITC) Toxicity Management Working Group. J Immunother Cancer 2017;5:1-28.

10. Papaioannou NE, Beniata OV, Vitsos P, et al. Harnessing the immune system to improve cancer therapy. Ann Transl Med 2016;4:261.

11. Cappelli LC, Gutierrez AK, Bingham CO, et al. Rheumatic and musculoskeletal immune-related adverse events due to immune checkpoint inhibitors: a systematic review of the literature. Arthritis Care Res 2017;69:1751-1763.

12. Zimmer L, Goldinger SM, Hofmann L, et al. Neurological, respiratory, musculoskeletal, cardiac and ocular side-effects of anti-PD-1 therapy. Eur J Cancer 2016;60: 210-225.

13. Kao JC, Liao B, Markovic SN, et al. Neurological complications associated with anti-programmed death 1 (PD-1). Antibodies JAMA Neurol 2017;74:1216-1222.

14. Läubli H, Hench J, Stanczak M, et al. Cerebral vasculitis mimicking intracranial metastatic progression of lung cancer during PD-1 blockade. J Immunother Cancer 2017;5:46.

15. Dasanu CA. Gemcitabine: vascular toxicity and prothrombotic potential. Expert Opin Drug Saf 2008;7:703-716.

16. Schmorl P, Heer-Sonderhoff A, Vosshenrich R, et al. Vaskulitis unter Gemcitabin [Cerebral vasculitis associated with gemcitabine]. Der Urologe 2010;49:268-270. 


\section{Neurology}

\section{Clinical Reasoning: A 77-year-old man presenting with episodic expressive aphasia}

Alice Shanklin, Andrew Cox, Hamdy M.A. Ahmed, et al.

Neurology 2018;90;e1822-e1826

DOI 10.1212/WNL.0000000000005525

\section{This information is current as of May 14, 2018}

\section{Updated Information \& Services}

References

Subspecialty Collections

Permissions \& Licensing

Reprints including high resolution figures, can be found at: http://n.neurology.org/content/90/20/e1822.full

This article cites 15 articles, 3 of which you can access for free at: http://n.neurology.org/content/90/20/e1822.full\#ref-list-1

This article, along with others on similar topics, appears in the following collection(s):

\section{All Cerebrovascular disease/Stroke}

http://n.neurology.org/cgi/collection/all_cerebrovascular_disease_strok e

Autoimmune diseases

http://n.neurology.org/cgi/collection/autoimmune_diseases Vasculitis

http://n.neurology.org/cgi/collection/vasculitis

Information about reproducing this article in parts (figures,tables) or in its entirety can be found online at:

http://www.neurology.org/about/about_the_journal\#permissions

Information about ordering reprints can be found online:

http://n.neurology.org/subscribers/advertise

Neurology ${ }^{\circledR}$ is the official journal of the American Academy of Neurology. Published continuously since 1951, it is now a weekly with 48 issues per year. Copyright @ 2018 American Academy of Neurology. All rights reserved. Print ISSN: 0028-3878. Online ISSN: 1526-632X.

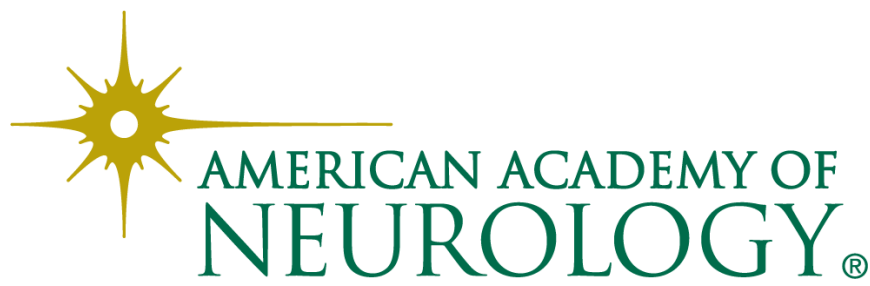

